\title{
Correction to: Atmospheric Turbulence Measurements at a Coastal Zone with and without Fog
}

\author{
Andrey A. Grachev ${ }^{1,2,3,5}$ (D) Raghavendra Krishnamurthy ${ }^{3,4}$. \\ Harindra J. S. Fernando ${ }^{3}$. Christopher W. Fairall ${ }^{1}$. Stef L. Bardoel ${ }^{3}$. Sen Wang $^{3}$ \\ Published online: 6 October 2021 \\ ๑) Springer Nature B.V. 2021
}

\section{Correction to: Boundary-Layer Meteorology https://doi.org/10.1007/s10546-021-00655-9}

In the original publication, the last sentence in caption of Fig. 11 was published incompletely. The correct caption for the figure is provided in this correction.

The original article has been corrected.

The original article can be found online at https://doi.org/10.1007/s10546-021-00655-9.

$\bowtie$ Andrey A. Grachev

Andrey.Grachev@colorado.edu

1 NOAA Physical Sciences Laboratory, Boulder, CO, USA

2 Cooperative Institute for Research in Environmental Sciences, University of Colorado, Boulder, CO, USA

3 Department of Civil and Environmental Engineering and Earth Sciences, Department of Aerospace and Mechanical Engineering, University of Notre Dame, Notre Dame, IN, USA

4 Pacific Northwest National Laboratory, Richland, WA, USA

5 Boundary Layer Research Team/Atmospheric Dynamics and Analytics Branch, DEVCOM Army Research Laboratory, White Sands, NM, USA 

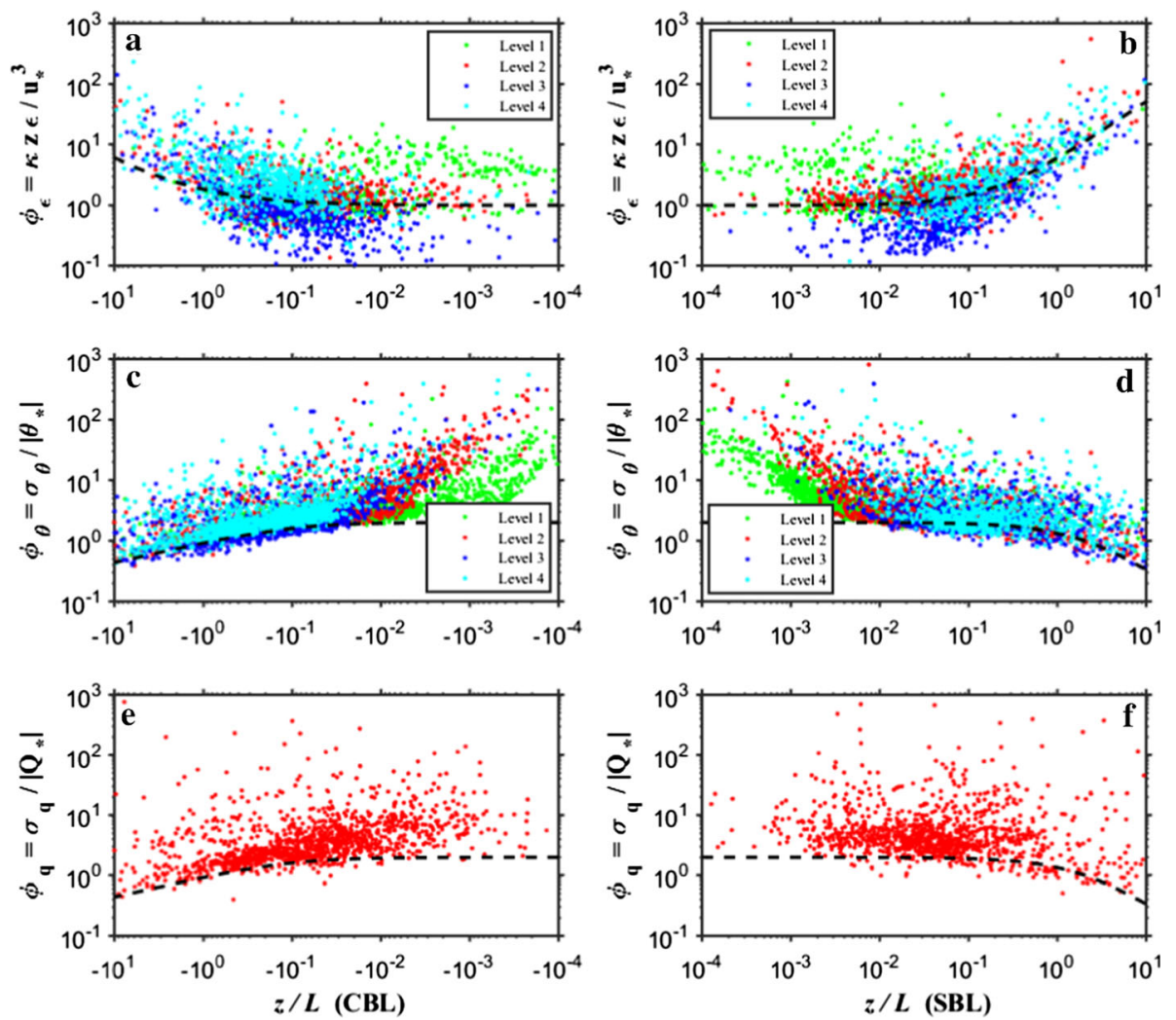

Fig. 11 The non-dimensional; a, b dissipation rate of TKE (9), and standard deviations of the; c, d air temperature (7), and e, f specific humidity (8) plotted in log-log coordinates versus the local Monin-Obukhov stability parameter (5) for the 15-min-averaged data collected during only clear sky days with high visibility (i.e., fog-free conditions) when the PWD22 visibility was greater than $6 \mathrm{~km}$. Plots in the left panels; a, c, e correspond to unstable conditions, or $\mathrm{CBL}, \zeta<0$; the right panels $\mathbf{b}$, d, f represent stable conditions, or SBL, $\zeta>0$. The black dashed lines correspond to $\varphi_{\varepsilon}(\zeta)=\left(1+0.5|\zeta|^{2 / 3}\right)^{3 / 2}$ for $\zeta<0$ and $\varphi_{\varepsilon}(\zeta)=(1+5 \zeta)$ for $\zeta>0$; and $\varphi_{\theta}(\zeta)=\varphi_{q}(\zeta)=2(1-9.5 \zeta)^{-1 / 3}$ for $\zeta<0$ and $\varphi_{\theta}(\zeta)=\varphi_{q}(\zeta)=2(1+0.5 \zeta)^{-1}$ for $\zeta>0$ (Kaimal and Finnigan 1994)

Publisher's Note Springer Nature remains neutral with regard to jurisdictional claims in published maps and institutional affiliations. 